OPEN ACCESS

Edited by:

Diego Albani,

Istituto di Ricerche Farmacologiche Mario Negri-IRCCS, Italy

Reviewed by:

Catarina Oliveira, University of Coimbra, Portugal

Peter Pimpl,

University of Tuebingen, Germany

${ }^{*}$ Correspondence:

Lifeng Yang

yanglf@cau.edu.cn

Received: 04 December 2015 Accepted: 15 February 2016

Published: 01 March 2016

Citation:

Li C, Shah SZA, Zhao D and Yang L (2016) Role of the Retromer Complex

in Neurodegenerative Diseases.

Front. Aging Neurosci. 8:42.

doi: 10.3389/fnagi.2016.00042

\section{Role of the Retromer Complex in Neurodegenerative Diseases}

\author{
Chaosi Li, Syed Zahid Ali Shah, Deming Zhao and Lifeng Yang* \\ National Animal Transmissible Spongiform Encephalopathy Laboratory, Key Laboratory of Animal Epidemiology and Zoonosis \\ of Ministry of Agriculture, College of Veterinary Medicine and State Key Laboratory of Agrobiotechnology, China Agricultural \\ University, Beijing, China
}

The retromer complex is a protein complex that plays a central role in endosomal trafficking. Retromer dysfunction has been linked to a growing number of neurological disorders. The process of intracellular trafficking and recycling is crucial for maintaining normal intracellular homeostasis, which is partly achieved through the activity of the retromer complex. The retromer complex plays a primary role in sorting endosomal cargo back to the cell surface for reuse, to the trans-Golgi network (TGN), or alternatively to specialized endomembrane compartments, in which the cargo is not subjected to lysosomal-mediated degradation. In most cases, the retromer acts as a core that interacts with associated proteins, including sorting nexin family member 27 (SNX27), members of the vacuolar protein sorting 10 (VPS10) receptor family, the major endosomal actin polymerization-promoting complex known as Wiskott-Aldrich syndrome protein and scar homolog (WASH), and other proteins. Some of the molecules carried by the retromer complex are risk factors for neurodegenerative diseases. Defects such as haplo-insufficiency or mutations in one or several units of the retromer complex lead to various pathologies. Here, we summarize the molecular architecture of the retromer complex and the roles of this system in intracellular trafficking related the pathogenesis of neurodegenerative diseases.

Keywords: retromer complex, sorting nexin family member 27, Wiskott-Aldrich syndrome protein and scar homolog, Alzheimer's disease, Parkinson's disease

\section{INTRODUCTION}

Cargo originating from the plasma membrane (PM) and biosynthetic pathways is internalized to endosomes through endocytosis, after which cargo proteins are recruited to different destinations for many cellular activities. Internalized nutrients are targeted to different organelles for processing, pathogens are transported into lysosomes for degradation, and newly synthesized proteins are transported to specific cellular locations for specific functions (Lakadamyali et al., 2006). The cargo sorting retromer complex, a membrane coat complex that is a crucial mediator of endosomal protein sorting, was first identified in yeast as a peripheral membrane protein complex (Seaman, 2004). Internalized cargoes are sorted by the retromer complex in three different ways (Figure 1). First, in the recycling pathway, proteins such as nutrient transporters, mitogenic signaling receptors, and cell adhesion receptors are recycled from endosomes to the PM for reuse (Maxfield and McGraw, 2004; Hsu et al., 2012). The second pathway is a retrograde pathway in which cargo is trafficked from the endosomes to the trans-Golgi network (TGN). The principal cargoes of the retrograde pathways are sorting receptors, soluble N-ethylmaleimide-sensitive 


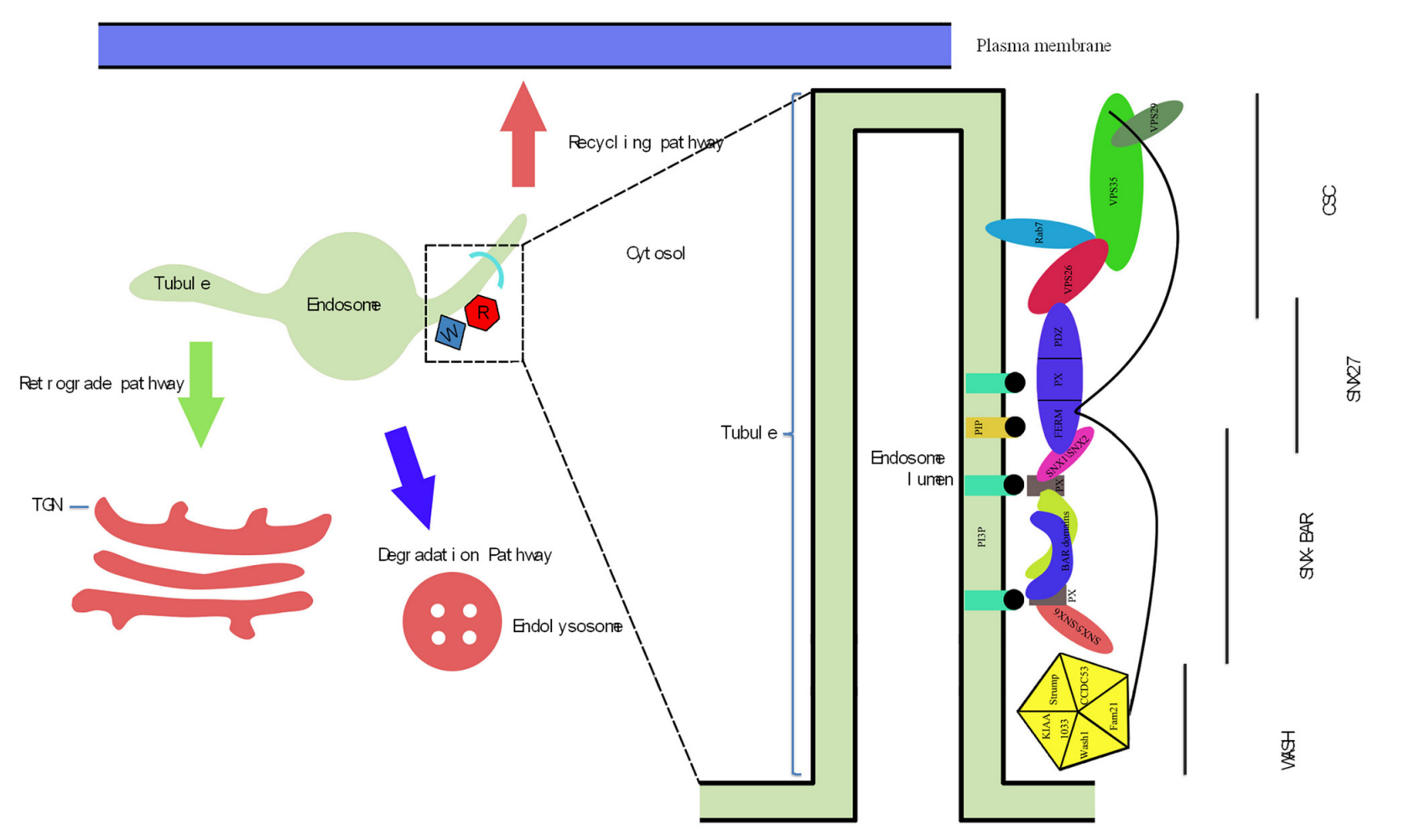

FIGURE 1 | The endosomal trafficking managed by retromer and the molecular architecture of inter-relationship between the retromer complex, sorting nexin family member 27 (SNX27) and Wiskott-Aldrich syndrome protein and scar homolog (WASH) complex. (1) There are three trafficking pathways regulated by retromer. Initially, the retrograde pathway, cargo proteins are retrieved from the endosomes and trafficked to the trans-Golgi network (TGN). The second is the recycling pathway in which cargo proteins are trafficked to the plasma membrane (PM) for reuse. The first two transport routes above both via tubules depended that extend out of edosomal membranes. The last pathway is degradative pathway, which helps in internalizing cargoes to the endosome then gradually matures to become the multi-vesicular late endosome (LE) before fusing to existing lysosomes resulting in the degradation of cargoes in the endolysosome. (2) The endosomal-sorting complex is composed of retromer complex, SNX27 and WASH complex. The WASH complex is comprised of five proteins: KIAA1033, Strumpellin, FAM21, WASH1, and Coiled-Coil Domain Containing 53 (CCDC53). SNX27 is composed of protein-interaction domains often found in multi-domain scaffolding proteins known as PDZ domain, the phoxhomology (PX) domain and the FERM domain. Retromer complex consist of cargo-selective complex (CSC; VPS35, VPS26 and VPS29) and SNX-BAR (SNX1 or SNX2 and SNX5 or SNX6). VPS35 supports a platform that VPS26 and VPS29 bind to it. Rab7 interacts with VPS26 and VPS35 as well as recruits the CSC to the endosome membrane. VPS26 binds to the PDZ domain of SNX27. The FERM-like domain of the SNX27 directly interacts with SNX1 or SNX2 of SNX-BAR. The recruitment of SNX27 and SNX-BAR to endosomes is both through the binding of phosphatidylinositol-3-phosphate (PI3P) by their PX domain. In addition, within the FERM domain of SNX27, is a second site with high affinity for PIP. As for the WASH complex, which is responsible to link itself to the VPS35, VPS29 and SNX27 FERM domain through its unstructured C-terminal tail in FAM21 and is recruited by CSC.

factor attachment protein receptors (SNAREs), and other molecules with functions dependent on continual retrieval from the endosomal system and return to biosynthetic pathways (Bonifacino and Rojas, 2006; Johannes and Popoff, 2008). The third pathway is a degradative pathway that involves internalization of cargoes on the PM into early endosomes (EEs), which gradually mature into multi-vesicular late endosomes (LEs) and fuse to existing lysosomes, resulting in degradation of endolysosomal cargo (Cullen and Korswagen, 2012). The retromer complex recruits membrane cargoes from the vacuolar domain to retromer-decorated tubular domains for retrieval and recycling; such cargoes can be selectively trafficked to avoid transportation to LEs and subsequent degradation (Lu and Hong, 2014). Therefore, the retromer complex plays a role in limiting lysosome-mediated turnover. During this process, the retromer complex recruits additional proteins that capture and package cargoes and direct them to alternate sorting fates. Normally, there is a coordinated relationship between the recycling, retrograde, and degradative pathways, which maintains cellular metabolic balance and homeostasis. However, if any of the above-mentioned pathways are hampered by events such as deregulated protein processing or missorting of intracellular proteins within endosomal-lysosomal pathways, deficiencies in cargo sorting, organelle development, and signal transduction can occur, sometimes leading to protein misfolding disorders (PMDs), including Alzheimer's disease (AD), Parkinson's disease (PD), frontotemporal lobar degeneration (FTLD), and Down's syndrome (Reitz, 2015).

\section{RETROMER AND ITS PARTNER PROTEINS}

\section{Sorting Nexin Bar (SNX-BAR)}

Retromer is composed of two sub-protein complexes. In addition to the cargo-selective complex (CSC), sorting nexins 
(SNX) form a hetero-dimer complex composed of vacuolar protein sorting 5 (VPS5) and VPS17 in yeast (Seaman et al., 1998). SNX proteins differ significantly between species. In metazoans, SNX-BAR family members include SNX1, SNX2, SNX5, and SNX6. SNX1 and SNX2 are VPS5 orthologs that originated from gene duplication in a vertebrate ancestor; however, SNX5 and SNX6 resulted from duplication of VPS17 in a metazoan ancestor (Harterink et al., 2011). All SNXs include two membrane-binding domains, a phox homology (PX) domain and Bin/Amphiphysin/Rvs domain (BAR), and are thus termed SXN-BAR proteins. The BAR domain resides at the C-terminal of SNX proteins. The PX domain is capable of sensing, formatting, and stabilizing membrane curvature by binding to membrane surfaces, leading to endosomal budding in yeast and mammalian cells (Carlton et al., 2004; Frost et al., 2009; van Weering et al., 2012). SNX-BAR dimers associate with the membrane independently of the CSC in mammalian cells (Seaman, 2004). SNX-BAR recruitment is mediated through binding to phosphatidylinositol 3-phosphate (PtdIns(3)P) in EEs in yeast and mammalian cells (Figure 1; Gillooly et al., 2000; Cozier et al., 2002; Harterink et al., 2011; Vardarajan et al., 2012). In LEs, phosphatidylinositol 3,5-bisphosphate $(\operatorname{PtdIns}(3,5) \mathrm{P} 2)$ is bound by the PX domain of SNX-BAR dimers in yeast and mammalian cells (Gillooly et al., 2000; Cozier et al., 2002; Huotari and Helenius, 2011; Jean and Kiger, 2012).

In addition to mediating retrograde transport between endosomes and the TGN, the SNX-BAR coat complex transports other molecules through tubular-based endosomal trafficking (Cullen, 2008). For example, SNX1 interacts with the tails of G-protein-coupled receptors (GPCRs) in vitro and traffics the GPCR protease-activated receptor-1 (PAR1) to the lysosome for degradation. In addition, SNX1 regulates recycling of the P2Y1 receptor, a GPCR, via a slow recycling pathway in mammalian cells (Wang et al., 2002; Heydorn et al., 2004; Nisar et al., 2010).

\section{Cargo Selective Complex}

In mammalian cells, the CSC is a highly conserved heterotrimer subcomplex consisting of VPS35, VPS26, and VPS29. The CSC evolved in a common eukaryotic ancestor. Among the three components of the CSC, VPS35 acts as the key component, providing linkage between VPS26 and VPS29 (Figure 1). Mammals express two VPS26 orthologs, VPS26A and VPS26B (Burd and Cullen, 2014), which possess an arresting fold and bind to the highly conserved amino-terminal region of VPS35 (Collins et al., 2005; Shi et al., 2006). However, an L108P mutation within the PRLYL conserved assembly motif of VPS35 blocks binding of VPS35 to VPS26 in yeast and mammalian cells (Gokool et al., 2007). VPS29 possesses a metallophosphoesterase fold and binds to the carboxy-terminal of VPS35, where it is proposed to bind with the helical solenoid of VPS35 in mammalian cells (Wang et al., 2005; Rojas et al., 2008; Norwood et al., 2011). The loss of function of the D620N VPS35 mutant was not as pronounced as that of the H675R mutant, which cannot bind VPS29 in yeast or mammalian cells (Zhao et al., 2007; Zavodszky et al., 2014). VPS35, VPS26, and VPS29 form a trimeric complex that does not have intrinsic membrane-binding activity. Retromer recruitment is mediated by RAS-related GTP-binding proteins (RABs). In humans, Rab7 (Ypt7 in yeast) binds to LEs via direct interaction with $\mathrm{N}$ terminal conserved regions in VPS35 and VPS26. In addition, amino-terminal residues (189-252) of VPS35 are essential for Rab7-mediated retromer recruitment in mammalian cells (Priya et al., 2015). In mammals, the binding sites of VPS35 and VPS26 on Rab7 are near each other (Priya et al., 2015). Importantly, association of VPS26 with VPS35 results in high affinity binding between the CSC and activated Rab7 (Priya et al., 2015). TBC1D5, a putative Rab GTPase-activating protein for Rab7, inhibits recruitment of the retromer CSC in mammalian cells (Rojas et al., 2008; Seaman et al., 2009; Vardarajan et al., 2012).

However, in EEs, the CSC is recruited through SNX3 bound to the membrane, where the retromer complex subsequently transports integral membrane retrograde cargo (Harrison et al., 2014). It would naturally follow that many membrane proteins require retromer for their localization; indeed, a recent proteomic study identified more than 100 proteins that were depleted from the cell surface following loss of retromer function in mammalian cells (Steinberg et al., 2013). In addition to sorting cargoes through direct binding, CSC also sorts cargoes by recruitment of accessory proteins, such as the Wiskott-Aldrich syndrome protein and scar homolog (WASH) complex, as well as binding of SNX27 with cargoes (Gomez and Billadeau, 2009; Harbour et al., 2010).

\section{Sorting Nexin 27 (SNX27)}

SNX27 is composed protein-interaction domains often found in multi-domain scaffolding proteins, including a PDZ domain, PX domain, and FERM domain (Figure 1). The PX domain is a phosphoinositide-binding domain that is conserved in yeast and humans. The FERM domain, originally identified in rats as an alternative-splicing product of the methamphetamine responsive transcript 1 (Mrt1) gene, is a widespread cytoskeleton protein module involved in localizing proteins to the PM in mammalian cells (Kajii et al., 2003). In an arrangement unique among PX domain proteins, the N-terminal PDZ domain of SNX27 is upstream of the PX domain; three sub domains, F1, F2, and F3, constitute the FERM-like domain at the C-terminal region of SNX27 in mammals (Ghai et al., 2011). Two associations with the SNX-BAR-retromer complex are displayed independently by SNX27. In addition to direct interaction of the FERM-like domain with SNX1 (and likely SNX2), the PDZ domain directly binds to VPS26, whereas the FERM-like domain combines with the unstructured C-terminal tail of FAM21, an unit of the WASH retromer accessory protein complex, in mammalian cells (Figure 1; Ghai et al., 2011).

In the pathway from endosomes to the PM, SNX27 acts as a retromer adapter and a major regulator of transport via binding with PDZ-binding motifs in mammalian cells (Cao et al., 1999; Temkin et al., 2011; Steinberg et al., 2013). In this pathway, the critical step is the recruitment of SNX27 to endosomes through binding of phosphatidylinositol-3-phosphate (PI3P) by the PX domain in T-cells (Ghai et al., 2015). In addition, the FERM domain contains a second site with high affinity for 
PtdInsP species, which are enriched at the PM and within LE compartments in T-cells. In other words, perturbing the interaction of the FERM domain with PtdInsP significantly reduces the association of SNX27 with endosomal recycling compartments (Ghai et al., 2015). Further studies revealed that an exposed $\beta$-hairpin in the PDZ domain of SNX27 in rats engages a groove in the arrestin-like structure of VPS26 (Gallon et al., 2014). This binding of SNX27 and VPS26 increases the affinity of the SNX27 PDZ domain for PDZ-binding motifs by an order of magnitude, revealing cooperation in cargo selection (Gallon et al., 2014). Indeed, cargoes such as NPxY/NxxY and a large group of G-protein coupled receptors (GPCRs) were trafficked in an SNX27-dependent manner from EEs to SNX-BAR-retromer-decorated tubules (Joubert et al., 2004; Lunn et al., 2007; Lauffer et al., 2010; Balana et al., 2011; Ghai et al., 2011; Temkin et al., 2011; Steinberg et al., 2013).

\section{Wiskott-Aldrich Protein and SCAR Homolog (WASH) Complex}

In addition to SNX27, the mammalian retromer complex recruits another primary protein complex called WASH, which contributes to precise trafficking of cargoes out of endosomes (Gomez and Billadeau, 2009; Harbour et al., 2010; Cullen and Carlton, 2012). The WASH complex was initially identified through affinity isolation of tagged WASH1 protein. The WASH complex is comprised of five proteins: KIAA1033 (also known as strumpellin and WASH-interacting protein (SWIP)), strumpellin, FAM21, WASH1, and coiled-coil domain containing 53 (CCDC53; Figure 1; Derivery et al., 2009; Gomez and Billadeau, 2009). Each WASH complex component is unstable and degrades if the other subunits are silenced in mammalian cells (Derivery et al., 2009; Jia et al., 2010; Seaman et al., 2013). These results strongly support the hypothesis that the proteins operate as an obligate complex in which they are dependent on each other (Gomez et al., 2012). FAM21 binds retromer through its unstructured C-terminal tail, which contains numerous repeated motifs called LFa motifs, and binds to the surface of endosomes in mammalian cells (Figure 1; Harbour et al., 2012). The two most C-terminal LFa motifs, R20 and R21, bind to the VPS35/VPS29 complex with the highest affinity; endosomal localization of FAM21 is abolished when R20 and R21 are deleted in mammalian cells (Jia et al., 2012; Hao et al., 2013). In addition, VPS35-VPS29 interaction is also critical for regulation of retromer association with the WASH complex; the H675R mutation in human VPS35 blocks binding to VPS29 and prevents association with FAM21 and the WASH complex (Helfer et al., 2013). The results described above suggest that CSC recruits the WASH complex to the endosomal surface.

The WASH complex and activated Arp2/3 facilitate actin polymerization and mediate patch formation on endosomes (Derivery et al., 2009; Gomez and Billadeau, 2009). Discrete actin patches may provide a platform for specialized signaling events; rapid elongation of actin filaments can generate a localized force that may be involved in the formation and maturation of endosomal tubules through which internalized transmembrane proteins are generally thought to exit the cell (Maxfield and McGraw, 2004; Bonifacino and Rojas, 2006). Finally, Mvp1 promotes VPS1-mediated fission of retromer and coats tubules that bud from the endosome (Chi et al., 2014). Therefore, WASH plays a major role in retromer-dependent endosomal trafficking.

Recent studies have extended the CSC interactome (Steinberg et al., 2013), but very few CSC interactomes have been subjected to comprehensive study; therefore, further research is needed to thoroughly study all CSC interactomes. Some molecules reported to interact with retromer or its accessory proteins play significant roles in various neurodegenerative diseases.

\section{RETROMER AND NEURODEGENERATIVE DISEASES}

\section{Alzheimer's Disease}

$\mathrm{AD}$ is a major cause of dementia in the developed world. Abnormal accumulation of neurotoxic amyloid beta $(A \beta)$ peptides produced by cleavage of amyloid precursor protein (APP) is the hallmark of AD (Small and Duff, 2008). APP can be processed through amyloidogenic and non-amyloidogenic pathways. At the PM, most APP molecules are cleaved by $\beta$-secretase, releasing soluble APP (sAPP). However some precursor molecules escape this non-amyloidogenic pathway and are internalized via the endocytic pathway, following trafficking from endosomal compartments to the TGN or endolysosomes. Within endosomal compartments and the TGN, APP is sequentially cleaved by $\beta$-secretase (BACE) and $\gamma$ secretase, resulting in formation of $A \beta$ peptides of varying lengths, including $A \beta 40$ and $A \beta 42$ (Choy et al., 2012).

In 2005, reduced protein levels of VPS35 and VPS26 were found in the entorhinal cortex of brains from $\mathrm{AD}$ patients, leading to increased focus on the role of retromer in $\mathrm{AD}$ pathogenesis. In mice, VPS35 haploinsufficiency increases A $\beta$ protein levels, whereas deficiencies in the retromer-sorting pathway increase the length of time that APP resides in the endosomes; both effects can be linked to late-onset $\mathrm{AD}$. In flies, disruption of retromer function decreases secretion of $A \beta 40$, increasing the $A \beta 42: A \beta 40$ ratio and causing $A \beta$ to aggregate into neurotoxic oligomers and amyloid plaques, leading to hippocampal-dependent memory deficits and synaptic dysfunction (Small et al., 2005; Wen et al., 2011; Bhalla et al., 2012; Vardarajan et al., 2012; Muhammad et al., 2008; Sullivan et al., 2011). Therefore, retromer may take part in APP metabolism, possibly by influencing trafficking of APP from the endosomes to the TGN (Choy et al., 2012). Direct binding between APP and the retromer complex has not been reported (Andersen et al., 2005; Wen et al., 2011); however, several proteins that participate in APP trafficking and processing are dependent on retromer trafficking, including sortilin-related receptors SORLA and SORCS1, BACE1, and some phagocytosis receptors related to $A \beta$ (Gustafsen et al., 2013).

BACE1 and $\gamma$-secretase contribute critically to abnormal APP metabolism. VPS35 dysfunction in the mouse hippocampus 
increased BACE1 activity, whereas suppression of BACE1 expression rescued VPS35 deficiency (Wen et al., 2011; Wang et al., 2012). Suppression of VPS35 or VPS26 expression in cultured cells decreased BACE1 trans-Golgi localization (Wen et al., 2011). The VPS10p domain-sorting receptor sortilin is also required for retromer-mediated retrieval of BACE1 from endosomes to the TGN (Tan and Evin, 2012). Deletion of the intracellular domain of sortilin, containing the putative retromer-binding domain, increased endosomal localization of sortilin and BACE1 (Lane et al., 2012). In addition, interfering with SNX6 expression increased BACE1-dependent secretion of sAPPand cell-associated fragment $\mathrm{C} 99$, as well as $\mathrm{A} \beta$ generation (Okada et al., 2010). With respect to $\gamma$-secretase, SNX27 physically binds to PS1, a subunit of $\gamma$-secretase, and disrupts the integrity of the complex, thus inhibiting APP proteolysis (Wang et al., 2014). These results demonstrate the crucial function of the retromer complex in suppression of AD neuropathology and inhibition of BACE1 activation and $\mathrm{A} \beta$ production, which are mediated by promoting BACE1 endosome-to-Golgi retrieval.

SorLA/LR11 belongs to a family of VPS10-containing receptors and is expressed in neurons. Transcription of SORL1, the gene encoding SORLA, is down-regulated in patients suffering from sporadic AD. In addition, SORLA interacts directly with APP in N2a cells (Scherzer et al., 2004; Andersen et al., 2005; Schmidt et al., 2007; Mehmedbasic et al., 2015). Ablation of sortilin expression in mice results in accumulation of $\mathrm{A} \beta$ in the brain, implying that low SorLA expression may be a risk factor for developing $\mathrm{AD}$. SorLA slows the exit of APP from the TGN into the secretory pathway, inhibiting the formation of APP homodimers, the preferred substrates of secretase (Figure 2; Rogaeva et al., 2007; Schmidt et al., 2012). SORL1 acts as a molecular link between APP and BACE and inhibits the interaction between BACE and APP in the Golgi apparatus, reducing APP cleavage (Figure 2). However, SorLA only inhibits APP processing when located in the TGN, where its CR-cluster is essential for binding; deletion of the CR-cluster abolishes the protective effects of SorLA against APP processing (Fjorback and Andersen, 2012; Mehmedbasic et al., 2015), indicating that SorLA functions as a TGN retention factor for APP. Retromer mediates retrograde transport of SorLA through direct interaction between VPS26 and the cytoplasmic tail of SorLA; when this interaction is disrupted, SorLA can be transported to the TGN and interact with newly synthesized APP (Fjorback and Andersen, 2012). Consequently, overexpression of SorLA may reduce the abundance of $A \beta$ and inhibit $A \beta$ aggregation, perhaps slowing the progression of neurodegeneration associated with $\mathrm{AD}$.

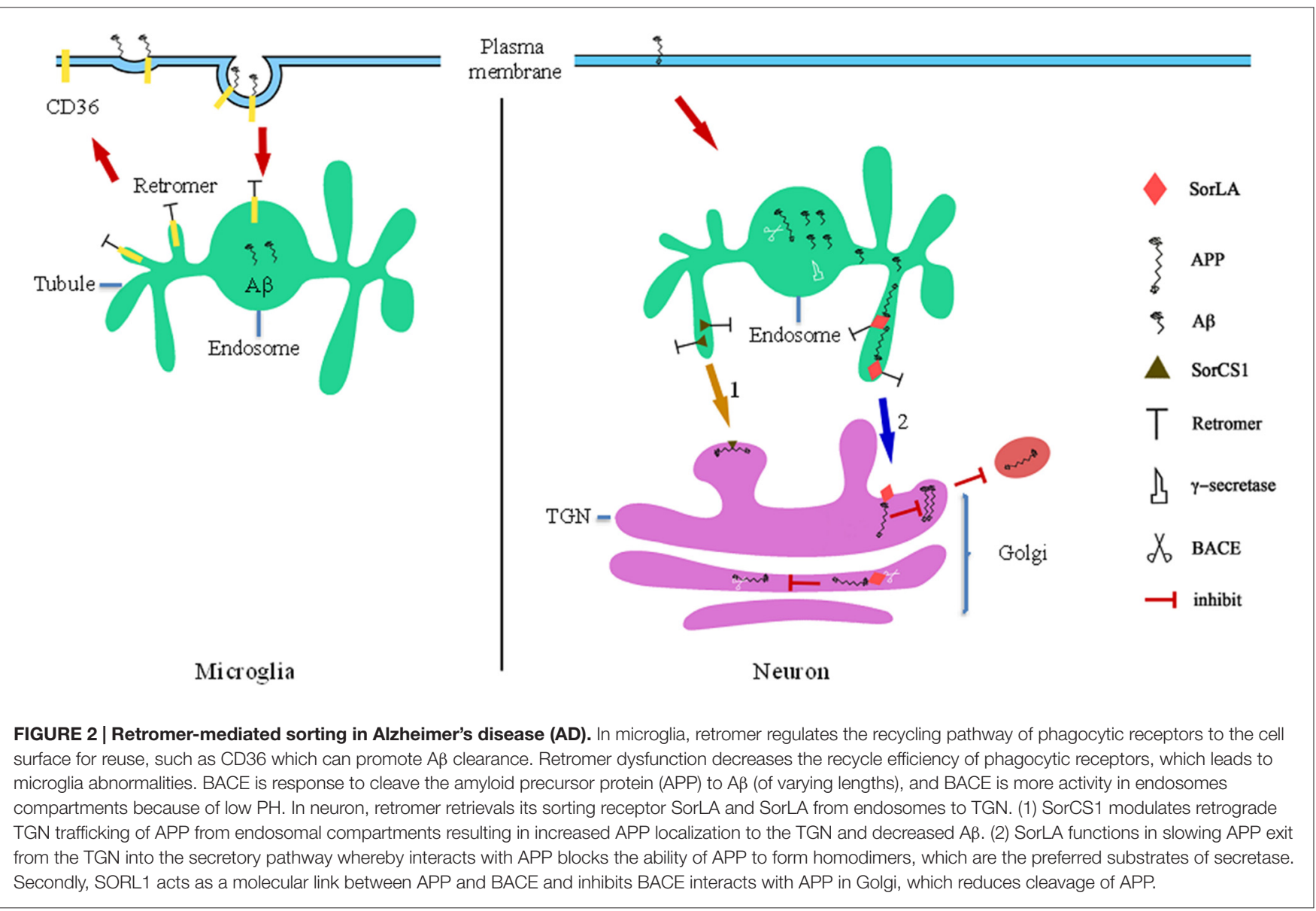


SorCS1 is a VPS10 domain-containing protein that shows significantly reduced expression levels in amygdala from $\mathrm{AD}$ brains. In cultured cells, SorCS1 interacts with APP and regulates $\mathrm{A} \beta$ generation (Reitz et al., 2011). In the brains of wild-type mice, SorCS1 forms a complex with APP, SorL1, and VPS35 (Lane et al., 2013). In the brains of female SorCS1-deficient mice, VPS35 abundance is decreased, while A $\beta$ abundance is increased, providing further evidence of the role of SorCS1 in regulating $\mathrm{A} \beta$ generation and implicating retromer in such regulation (Lane et al., 2010). Initially, reduced SorCS1 expression facilitated APP processing by $\gamma$-secretase (Reitz et al., 2011). SorCS1 modulates retrograde TGN trafficking of APP and/or APP C-terminal fragments (CTF) from endosomal compartments (Figure 2); its cytoplasmic tail motif YAQM facilitated APP localization to the TGN and decreased $A \beta$ production in $\mathrm{H} 4$ neuroglioma cells (Lane et al., 2013). Therefore, within low $\mathrm{pH}$ endosomal compartments, especially in LEs, APP is cleaved by $\mathrm{BACE}$ and $\gamma$-secretase, followed by formation of $\mathrm{A} \beta(\mathrm{Xu}, 2009)$. However, sorting of SorCS1 from endosomes to the TGN is dependent on retromer (Figure 2; Hermey, 2009; Lane et al., 2013). In addition, retromer may also take part in SorCS1dependent endosome-to-lysosome trafficking of APP/APP CTFs. The results described above demonstrate that low expression levels of SORLA and SORCS1 causes pathogenic processing of APP by decreasing the time that APP resides in the TGN; therefore, we hypothesize that increasing expression of SORLA and SORCS1 or facilitating trafficking of these proteins from endosomes to the TGN might have protective effects against AD.

Apart from impacting APP processing, recent studies found that microglia from the brains of human patients with $\mathrm{AD}$ exhibit reduced retromer expression and a decreased rate of $A \beta$ phagocytosis. Phagocytosis receptors, including CD36, tripartite motif containing 2 (Trim2), and class A1 scavenger receptors (Scara1), function in the clearance of extracellular proteins, including A $\beta$ (Prada et al., 2006; Frenkel et al., 2013; Lucin et al., 2013). During the process of phagocytosis, phagocytosis receptors interact with ligands and are taken into the cell. Subsequently, phagocytosis receptors are recycled to the PM for reuse (Freeman and Grinstein, 2014). Therefore, to some extent, the recycling efficiency of the phagocytosis receptor controls the clearance efficiency of its ligand. Decreased retromer expression impacts the recycling efficiency of CD36 and Trim2 from endosomes to the PM, inhibiting $\mathrm{A} \beta$ clearance (Figure 2; Lucin et al., 2013). The results described above suggest that recovering the abundance of retromer in the microglia of $\mathrm{AD}$ patients may enhance phagocytic efficiency and induce removal of $\mathrm{A} \beta$ aggregates.

Other $\mathrm{AD}$ risk genes, including SNX1, SNX3, and RAB7A, are involved in the cargo-selective retromer complex, demonstrating the direct link between the activity of the retromer complex and the pathogenesis of AD (Vardarajan et al., 2012).

\section{Parkinson's Disease}

$\mathrm{PD}$ is the second most common neurodegenerative disease worldwide after $\mathrm{AD}$. PD is associated with two main pathological hallmarks: loss of pigmented dopaminergic (DA) neurons in the substantia nigra pars compacta and the presence of Lewy bodies composed primarily of $\alpha$-synuclein ( $\alpha \mathrm{SYN}$ ) fibrils (Spillantini et al., 1997).

Utilizing exosome sequencing, two independent research groups identified the same mutation in the VPS35 gene (P.D620N) as the first disease-causing gene for PD (VilariñoGüell et al., 2011). In the following years, the D620N mutation in VPS35 was identified, leading researchers to focus on this mutation as the probable disease-causing pathogenic gene in autosomal dominant familial or late-onset autosomal dominant PD patients (Vilariño-Güell et al., 2011; Zimprich, 2011; Ando et al., 2012). Overexpression of VPS35 or VPS26 significantly protected VPS $35^{D A T-C r e}$ mice from locomotor deficits, while increasing the shortened life span of Drosophila serving as a model of PD (Linhart et al., 2014; Miura et al., 2014; Tang et al., 2015). In addition, VPS35 protein suppressed $\alpha$ SYN expression in a prion-like seeding model in transgenic mice, protecting the mice from neurodegeneration (Linhart et al., 2014; Ross et al., 2015). Finally, the retromer complex can mask the toxic effects of alterations in levels of translation initiation factor expression (Ross et al., 2015). These results suggest that retromer plays a crucial role in the development of PD.

Two studies suggest that loss of DA neurons in patients with $\mathrm{PD}$ is caused by mitochondrial dysfunction. In DA neurons, VPS35 deficiency, loss, or mutation (P.D620N) increased the half-life and protein level of mitochondrial E3 ubiquitin ligase-1 (MUL1) and led to mitofusin-2 (MFN2) ubiquitination and degradation, thus leading to mitochondrial fragmentation and DA neuron loss (Tang et al., 2015). Another study verified that mitochondrial deficits in neurons were caused by P.D620Nenhanced interaction of the dynamin-like protein 1 (DLP1) complex with VPS35, resulting in abnormal transport of DLP1 to the lysosomes for degradation (Wang et al., 2016). DLP1 is as an inhibitor of mitochondrial fission events (Chan, 2006). Synaptic dysfunction may also lead to neuronal death. The p.D620N mutation inhibits recycling of AMPA-type glutamate receptors (AMPARs), which mediate the vast majority of excitatory transmission within CNS to the PM (Figure 3). Such perturbations to synaptic function likely produce chronic pathophysiological stress upon neuronal circuits that may contribute to neurodegeneration in this form, and other forms of Parkinsonisms (Munsie et al., 2015). The studies described above demonstrate that retromer defects lead to neuron death.

The pathogenic oligomers formed by various intermediate states of $\alpha \mathrm{SYN}$ are suspected to be the toxic species underlying PD. Fc $\gamma$ RIIB contributes to phagocytosis of $\alpha \mathrm{SYN}$ into the cell (Wales et al., 2013; Choi et al., 2015). Aspartyl protease cathepsin D (CTSD), a lysosomal enzyme, is responsible for degradation of long-lived aSYN (Cullen et al., 2009). Under physiological conditions, cation-independent mannose-6phosphate receptor (CI-M6PR) is mainly localized in the TGN and LEs in the perinuclear space. Newly synthesized CTSD binds CI-M6PR in the TGN and is subsequently translocated into endosomes (Figure 3). Once at the endosomes, CTSD is released from CI-M6PR and awaits the next opportunity for transport to the lysosomes, at which point it becomes active 


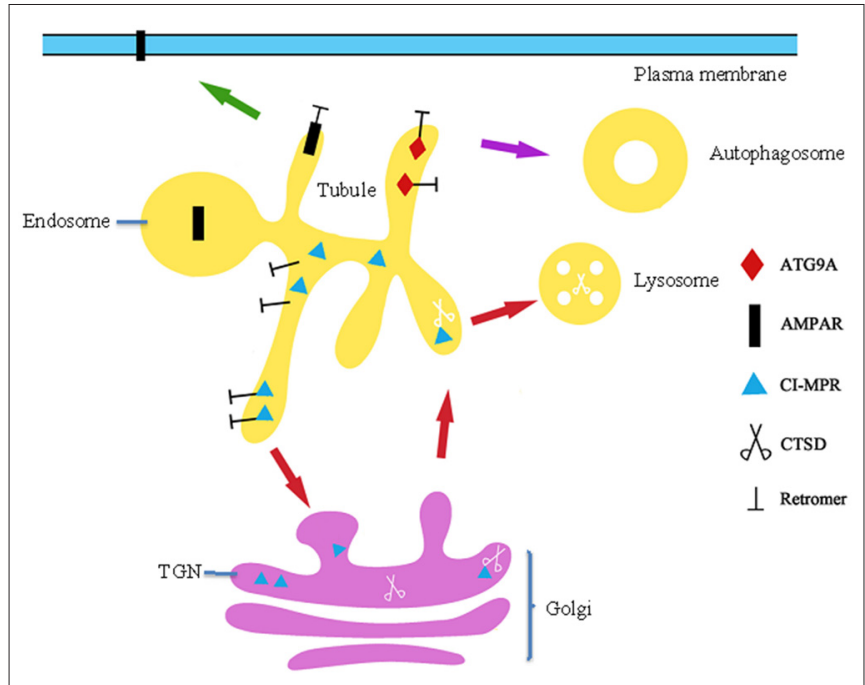

FIGURE 3 | The role of retromer in trafficking of AMPAR, ATG9A and CI-MPR. Firstly, retromer is response for recycle of AMPA type glutamate receptor (AMPAR) to the PM that mediates vast majority of excitatory transmission with CNS and excitatory synaptic transmission. Secondly, Retromer in charge of transport autophagy-related protein ATG9A to the autophagosomes, mutation p.D620N affects ATG9A localization and trafficking results in impaired autophagosomes formation. Finally, retromer retrieves unoccupied CI-MPRs in endosomes and traffics them to the TGN where they take part in cycles of CTSD to the lysosomes.

(Figure 3; Miura et al., 2014). Retromer retrieves unoccupied CIM6PRs from endosomes and traffics them to the TGN, where they take part in further cycles of CTSD sorting (Figure 3). However, p.D620N leads to a perturbation of CI-M6PR in endosome-to-TGN transport and results in a more scattered distribution of CI-M6PR in the periphery, markedly impacting processing of CTSD into the mature $20 \mathrm{kDa}$ active form and thus leading to abnormal $\alpha \mathrm{SYN}$ accumulation (Follett et al., 2014; McGough et al., 2014; Zavodszky et al., 2014). Silencing of VPS35 in cultured cells also reduced the distribution of CI-MPR and impairs maturation of CTSD concomitant with striking accumulation of $\alpha \mathrm{SYN}$ in the lysosomes, which may contribute to the pathogenesis of PD (Miura et al., 2014). Autophagosomes have been implicated as an intracellular site in which aggregations of $\alpha \mathrm{SYN}$ are cleared. In 2012, Dengjel used quantitative proteomics to identify VPS35 as a stimulus-dependent interacting partner of autophagosomes in human breast cancer cells, while a more recent study demonstrated that VPS35 directly interacts with and retrieves Atg8 in Magnaporthe oryzae (Dengjel et al., 2012). These studies suggest that retromer is closely related to the formation of autophagosomes in mammalian cells. Because p.D620N poorly binds with the WASH complex and impairs recruitment of WASH to endosomes, the affinity of p.D620N/VPS29 to R20 and R21 was significantly lower than that of the wild-type VPS35/VPS29 (McGough et al., 2014). This poor affinity affects autophagy-related protein ATG9A trafficking (Figure 3), while localization to the autophagosome impairs autophagosome formation, perhaps causing accumulation of $\alpha$ SYN (Zavodszky et al., 2014; Munsie et al., 2015). Although VPS26A and VPS29 interact with VPS35 in the CSC in the retromer complex, only two rare nonsynonymous variants (VPS26A, p.K93E; and VPS29, p.N72H) were identified in 702 PD patients, suggesting that mutations in VPS26A and VPS29 are not a frequent cause of PD (Koschmidder et al., 2014; Shannon et al., 2014; Gustavsson et al., 2015). VPS35 interacts genetically and functionally with translation initiator EIF4G1, a PD gene and scaffold protein on which the translation initiation complex assembles (Dhungel et al., 2015; Ross et al., 2015). Expression of VPS35 or sortilin proteins can suppress toxicity associated with EIF4G1 upregulation, masking the toxic effects of alterations in levels of translation initiation factor expression (Dhungel et al., 2015).

The studies mentioned above suggest that malfunction of VPS35 plays a primary role in the pathogenesis of PD, implying that overexpression of VPS35 may inhibit the development of PD and extend the lifespan of PD patients.

\section{Other Neurodegenerative Diseases}

Retromer participates in the pathogenesis of neurological disorders other than $\mathrm{AD}$ and $\mathrm{PD}$. In hereditary spastic paraplegia, three disease-causing mutations, V626F, L619F, and $\mathrm{N} 471 \mathrm{D}$, have been described in highly conserved sequences of strumpellin. Mutant strumpellin increases the vulnerability of corticospinal neurons, a pathological feature of hereditary spastic paraplegia (Freeman et al., 2013). In Down syndrome caused by over-expression of miR-155, a chromosome 21encoded micro RNA negatively regulates $\mathrm{C} / \mathrm{EBP} \beta$, a transcription factor that modulates SNX27 expression. Reduced SNX27 expression impacts glutamate receptor recycling to the PM in the hippocampus and produces grossly abnormal neuroanatomy, leading to synaptic dysfunction and deficits in learning and memory (Wang et al., 2013).

Endosomal transport of various pathogens, such as Salmonella, Herpesvirus saimiri, Coxiella burnetii, human papilloma virus, Legionella pneumophila, and Shiga toxins, is also mediated by the CSC (Bujny et al., 2007, 2008; Popoff et al., 2007; Kingston et al., 2011; Finsel et al., 2013; McDonough et al., 2013). Several pathogens interact directly with retromer, but the manner in which retromer interacts with many of its substrates is unknown.

\section{Conclusions and Future Perspectives}

The trend in pathophysiological research on neurodegenerative diseases is shifting from studying disease-specific, causative, misfolded proteins towards determining the pathways and protein complexes that may contribute to the pathogenesis of such diseases.

Interestingly, most neurodegenerative diseases have a close relationship with retromer complex defects (reduced expression or mutations). Reduced retromer levels were found in several parts of the brains of patients with $\mathrm{AD}$ or $\mathrm{PD}$, suggesting that reduced retromer abundance may have been associated with these conditions. Therefore, future studies should determine the potential of retromer as a therapeutic target for treatments intended for patients with neurological disorders. 
In patients with $\mathrm{AD}, \mathrm{PD}$, and prion diseases, inhibition of microglial phagocytosis results in aggregation of $\mathrm{A} \beta, \alpha \mathrm{SYN}$, and prion protein ( $\mathrm{PrP}^{\mathrm{Sc}}$; Ciesielski-Treska et al., 2004; Lucin et al., 2013; Choi et al., 2015). Several studies found that inhibition of microglial phagocytosis by defects in various receptors and proteins that participated in phagocytosis resulted in neurodegeneration and amyloidosis in mouse models of AD (Lu and Lemke, 2001; Wyss-Coray et al., 2002; Kaifu et al., 2003; Heneka et al., 2013). In contrast, microglial activation reduced $\mathrm{A} \beta$ pathology in mouse models of $\mathrm{AD}$ (Heneka et al., 2013). Retromer is critically involved in recycling phagocytosis receptors, including CD36, Trem2, and CED-1, to the PM for reuse; such recycling is vital for the clearance of misfolded proteins and cellular debris (Chen et al., 2010; Lucin et al., 2013; Abduljaleel et al., 2014). Increased abundance of retromer facilitated phagocytosis and reduced $A \beta$ plaque formation in the brains of APP transgenic mice by increasing the efficiency of phagocytosis receptor recycling (Lucin et al., 2013). These studies highlight the importance of retromer-mediated phagocytosis in brain homeostasis and suggest that retromer may represent a therapeutic target for the treatment of neurological diseases.

Retromer may also be a therapeutic target for treatments intended to relieve neuronal damage associated with neurodegenerative diseases. VPS35-deficiency leads to neuron loss in Tg2576 mice and DA neuron loss in young adult mice (Wen et al., 2011). However, deficient mitochondrial dynamics associated with neurodegenerative disorders is a factor in neuron loss (Tang et al., 2015). VPS35 plays a role in the formation of mitochondria-derived vesicles, suggesting that mitochondria may be a potential target site for VPS35 function. Expression of wild-type WVPS35 in VPS35-deficient cells restored mitochondrial morphology and function in DA neurons, as well as mitochondrial fission dynamics in fibroblasts (Tang et al., 2015; Wang et al., 2016). VPS35 suppressed MUL1-mediated

\section{REFERENCES}

Abduljaleel, Z., Al-Allaf, F. A., Khan, W., Athar, M., Shahzad, N., Taher, M. M., et al. (2014). Evidence of trem 2 variant associated with triple risk of Alzheimer's disease. PLoS One 9:e92648. doi: 10.1371/journal.pone.0092648

Andersen, O. M., Reiche, J., Schmidt, V., Gotthardt, M., Spoelgen, R., Behlke, J., et al. (2005). Neuronal sorting protein-related receptor sorLA/LR11 regulates processing of the amyloid precursor protein. Proc. Natl. Acad. Sci. U S A 102, 13461-13466. doi: 10.1073/pnas.0503689102

Ando, M., Funayama, M., Li, Y., Kashihara, K., Murakami, Y., Ishizu, N., et al. (2012). VPS35 mutation in Japanese patients with typical Parkinson's disease. Mov. Disord. 27, 1413-1417. doi: 10.1002/mds.25145

Balana, B., Maslennikov, I., Kwiatkowski, W., Stern, K. M., Bahima, L., Choe, S., et al. (2011). Mechanism underlying selective regulation of $\mathrm{G}$ proteingated inwardly rectifying potassium channels by the psychostimulant-sensitive sorting nexin 27. Proc. Natl. Acad. Sci. U S A 108, 5831-5836. doi: 10.1073/pnas. 1018645108

Bhalla, A., Vetanovetz, C. P., Morel, E., Chamoun, Z., Di Paolo, G., and Small, S. A. (2012). The location and trafficking routes of the neuronal retromer and its role in amyloid precursor protein transport. Neurobiol. Dis. 47, 126-134. doi: $10.1016 /$ j.nbd.2012.03.030

Bonifacino, J. S., and Rojas, R. (2006). Retrograde transport from endosomes to the trans-Golgi network. Nat. Rev. Mol. Cell Biol. 7, 568-579. doi: 10.1038/ nrm 1985
MFN2 degradation and promoted mitochondrial fusion (Züchner et al., 2004; Tang et al., 2015). However, MFN2-loss is implicated in the pathogenesis of Charcot-Marie-Tooth disease type 2A (Züchner et al., 2004). Altered mitochondrial morphology and dynamics were detected in VPS35-deficient DA neurons, as well as VPS35-depleted neuroblastoma and fibroblast cell lines (Tang et al., 2015; Wang et al., 2016). These results suggest that VPS35 may be a general regulator of mitochondrial fusion and fission dynamics in vitro, indicating that it could be a therapeutic target for treatments intended to prevent neuron loss in patients with neurodegenerative diseases.

In addition to the diseases mentioned above, retromer also plays a role in Creutzfeldt-Jakob disease (CJD), diabetes, and optic nerve injury (Kipkorir et al., 2014; Liu et al., 2014; Morabito et al., 2014). Future studies should determine why substantially decreased retromer expression was found in several parts of the brains of patients with the diseases mentioned above, but not in the whole brain. In addition, future studies should attempt to determine why retromer dysfunction occurs in specific neuronal populations. Comprehensive clinical studies are required to determine the potential of retromer as a therapeutic target.

\section{AUTHOR CONTRIBUTIONS}

CL wrote the manuscript. SZAS reviewed and edited the manuscript. LY and DZ provided the idea and gave useful advise during all major steps of writing the manuscript. All authors have read and approved the final manuscript.

\section{ACKNOWLEDGMENTS}

This work was supported by 948 projects (2014-S9) funded by Chinese ministry of agriculture and the Natural Science Foundation of China (Project No. 31472166).

Bujny, M. V., Ewels, P. A., Humphrey, S., Attar, N., Jepson, M. A., and Cullen, P. J. (2008). Sorting nexin-1 defines an early phase of Salmonella-containing vacuole-remodeling during Salmonella infection. J. Cell Sci. 121, 2027-2036. doi: $10.1242 / j \mathrm{jcs} .018432$

Bujny, M. V., Popoff, V., Johannes, L., and Cullen, P. J. (2007). The retromer component sorting nexin-1 is required for efficient retrograde transport of Shiga toxin from early endosome to the trans Golgi network. J. Cell Sci. 120, 2010-2021. doi: 10.1242/jcs.003111

Burd, C., and Cullen, P. J. (2014). Retromer: a master conductor of endosome sorting. Cold Spring Harb. Perspect. Biol. 6:a016774. doi: 10.1101/cshperspect. a016774

Cao, T. T., Deacon, H. W., Reczek, D., Bretscher, A., and von Zastrow, M. (1999). A kinase-regulated PDZ-domain interaction controls endocytic sorting of the B2-adrenergic receptor. Nature 401, 286-290. doi: 10.1038/45816

Carlton, J., Bujny, M., Peter, B. J., Oorschot, V. M., Rutherford, A., Mellor, H., et al. (2004). Sorting nexin-1 mediates tubular endosome-to-TGN transport through coincidence sensing of high- curvature membranes and 3-phosphoinositides. Curr. Biol. 14, 1791-1800. doi: 10.1016/j.cub.2004. 09.077

Chan, D. C. (2006). Mitochondrial fusion and fission in mammals. Annu. Rev. Cell. Dev. Biol. 22, 79-99. doi: 10.1146/annurev.cellbio.22.010305.104638

Chen, D. D., Xiao, H., Zhang, K., Wang, B., Gao, Z. Y., Jian, Y., et al. (2010). Retromer is required for apoptotic cell clearance by phagocytic receptor recycling. Science 327, 1261-1264. doi: 10.1126/science.1184840 
Chi, R. J., Liu, J. X., West, M., Wang, J., Odorizzi, G., and Burd, C. G. (2014). Fission of SNX-BAR-coated endosomal retrograde transport carriers is promoted by the dynamin-related protein Vps1. J. Cell Biol. 204, 793-806. doi: $10.1083 /$ jcb.201309084

Choi, Y. R., Kang, S. J., Kim, J. M., Lee, S. J., Jou, I., Joe, E. H., et al. (2015). FcgammaRIIB mediates the inhibitory effect of aggregated $\alpha$-synuclein on microglial phagocytosis. Neurobiol. Dis. 83, 90-99. doi: 10.1016/j.nbd.2015.08. 025

Choy, R. W., Cheng, Z., and Schekman, R. (2012). Amyloid precursor protein (APP) traffics from the cell surface via endosomes for amyloid beta $(\mathrm{A} \beta)$ production in the trans-Golgi network. Proc. Natl. Acad. Sci. U S A 109, E2077-E2082. doi: 10.1073/pnas.1208635109

Ciesielski-Treska, J., Grant, N. J., Ulrich, G., Corrotte, M., Bailly, Y., Haeberle, A. M., et al. (2004). Fibrillar prion peptide (106-126) and scrapie prion protein hamper phagocytosis in microglia. Glia 46, 101-115. doi: 10.1002/glia. 10363

Collins, B. M., Skinner, C. F., Watson, P. J., Seaman, M. N. J., and Owen, D. J. (2005). Vps29 has a phosphoesterase fold that acts as a protein interaction scaffold for retromer assembly. Nat. Struct. Mol. Biol. 12, 594-602. doi: 10. 1038/nsmb954

Cozier, G. E., Carlton, J., McGregor, A. H., Gleeson, P. A., Teasdale, B. D., Mellor, H., et al. (2002). The Phox Homology (PX) domain-dependent, 3phosphoinositide-mediated association of sorting nexin-1 with an early sorting endosomal compartment is required for its ability to regulate epidermal growth factor receptor degradation. J. Biol. Chem. 277, 48730-48736. doi: 10.1074/jbc. $\mathrm{m} 206986200$

Cullen, P. J. (2008). Endosomal sorting and signalling: an emerging role for sorting nexins. Nat. Rev. Mol. Cell Biol. 9, 574-582. doi: 10.1038/nrm2427

Cullen, P. J., and Carlton, J. G. (2012). Phosphoinositides in the mammalian endo-lysosomal network. Subcell. Biochem. 59, 65-110. doi: 10.1007/978-94007-3015-1_3

Cullen, P. J., and Korswagen, H. C. (2012). Sorting nexins provide diversity for retromer-dependent trafficking events. Nat. Cell Biol. 14, 29-37. doi: 10. 1038/ncb2374

Cullen, V., Lindfors, M., Ng, J., Paetau, A., Swinton, E., Kolodziej, P., et al. (2009). Cathepsin D expression level affects alpha-synuclein processing, aggregation and toxicity in vivo. Mol. Brain 2:5. doi: 10.1186/17566606-2-5

Dengjel, J., Høyer-Hansen, M., Nielsen, M. O., Eisenberg, T., Harder, L. M., Schandorff, S., et al. (2012). Identification of autophagosome-associated proteins and regulators by quantitative proteomic analysis and genetic screens. Mol. Cell. Proteomics 11:M111.014035. doi: 10.1074/mcp.m111. 014035

Derivery, E., Sousa, C., Gautier, J. J., Lombard, B., Loew, D., and Gautreau, A. (2009). The Arp $2 / 3$ activator WASH controls the fission of endosomes through a large multiprotein complex. Dev. Cell 17, 712-723. doi: 10.1016/j.devcel.2009. 09.010

Dhungel, N., Eleuteri, S., Li, L. B., Kramer, N. J., Chartron, J. W., Spencer, B., et al. (2015). Parkinson's disease genes VPS35 and EIF4G1 interact genetically and converge on alpha-synuclein. Neuron 85, 76-87. doi: 10.1016/j.neuron.2014. 11.027

Finsel, I., Ragaz, C., Hoffmann, C., Harrison, C. F., Weber, S., van Rahden, V. A., et al. (2013). The Legionella effector RidL inhibits retrograde trafficking to promote intracellular replication. Cell Host Microbe 14, 38-50. doi: 10.1016/j. chom.2013.06.001

Fjorback, A. W., and Andersen, O. M. (2012). SorLA is a molecular link for retromer-dependent sorting of the Amyloid precursor protein. Commun. Integr. Biol. 5, 616-619. doi: 10.4161/cib.21433

Follett, J., Norwood, S. J., Hamilton, N. A., Mohan, M., Kovtun, O., Tay, S., et al. (2014). The Vps35 D620N mutation linked to Parkinson's disease disrupts the cargo sorting function of retromer. Traffic 15, 230-244. doi: 10.1111/tra. 12136

Freeman, S. A., and Grinstein, S. (2014). Phagocytosis: receptors, signal integration and the cytoskeleton. Immunol. Rev. 262, 193-215. doi: 10.1111/imr.12212

Freeman, C., Seaman, M. N., and Reid, E. (2013). The hereditary spastic paraplegia protein strumpellin: characterisation in neurons and of the effect of disease mutations on WASH complex assembly and function. Biochim. Biophys. Acta 1832, 160-173. doi: 10.1016/j.bbadis.2012.10.011
Frenkel, D., Wilkinson, K., Zhao, L. Z., Hickman, S. E., Means, T. K., Puckett, L., et al. (2013). Scaral deficiency impairs clearance of soluble amyloid-beta by mononuclear phagocytes and accelerates Alzheimer's-like disease progression. Nat. Commun. 4:2030. doi: 10.1038/ncomms3030

Frost, A., Unger, V. M., and De Camilli, P. (2009). The BAR domain superfamily: membrane-molding macromolecules. Cell 137, 191-196. doi: 10.1016/j.cell. 2009.04.010

Gallon, M., Clairfeuille, T., Steinberg, F., Mas, C., Ghai, R., Sessions, R. B., et al. (2014). A unique PDZ domain and arrestin-like fold interaction reveals mechanistic details of endocytic recycling by SNX27-retromer. Proc. Natl. Acad. Sci. U S A 111, E3604-E3613. doi: 10.1073/pnas.1410 552111

Ghai, R., Mobli, M., Norwood, S. J., Bugarcic, A., Teasdale, R. D., King, G. F., et al. (2011). Phox homology band 4.1/ezrin/radixin/moesin-like proteins function as molecular scaffolds that interact with cargo receptors and Ras GTPases. Proc. Natl. Acad. Sci. U S A 108, 7763-7768. doi: 10.1073/pnas.10171 10108

Ghai, R., Tello-Lafoz, M., Norwood, S. J., Yang, Z., Clairfeuille, T., Teasdale, R. D., et al. (2015). Phosphoinositide binding by the SNX27 FERM domain regulates its localization at the immune synapse of activated T-cells. J. Cell Sci. 128, 553-565. doi: $10.1242 /$ jcs. 158204

Gillooly, D. J., Morrow, I. C., Lindsay, M., Gould, R., Bryant, N. J., Gaullier, J. M., et al. (2000). Localization of phosphatidylinositol 3-phosphate in yeast and mammalian cells. EMBO J. 19, 4577-4588. doi: 10.1093/emboj/19. 17.4577

Gokool, S., Tattersall, D., Reddy, J. V., and Seaman, M. N. J. (2007). Identification of a conserved motif required for $\mathrm{Vps} 35 / \mathrm{Vps} 26 \mathrm{p}$ interaction and assembly of the retromer complex. Biochem. J. 408, 287-295. doi: 10.1042/bj20070555

Gomez, T. S., and Billadeau, D. D. (2009). A FAM21-containing WASH complex regulates retromer-dependent sorting. Dev. Cell 17, 699-711. doi: 10.1016/j. devcel.2009.09.009

Gomez, T. S., Gorman, J. A., de Narvajas, A. A., Koenig, A. O., and Billadeau, D. D. (2012). Trafficking defects in WASH-knockout fibroblasts originate from collapsed endosomal and lysosomal networks. Mol. Biol. Cell 23, 3215-3228. doi: 10.1091/mbc.e12-02-0101

Gustafsen, C., Glerup, S., Pallesen, L. T., Olsen, D., Andersen, O. M., Nykjaer, A., et al. (2013). Sortilin and SorLA display distinct roles in processing and trafficking of amyloid precursor protein. J. Neurosci. 33, 64-71. doi: 10. 1523/JNEUROSCI.2371-12.2013

Gustavsson, E. K., Guella, I., Trinh, J., Szu-Tu, C., Rajput, A., Rajput, A. H., et al. (2015). Genetic variability of the retromer cargo recognition complex in parkinsonism. Mov. Disord. 30, 580-584. doi: 10.1002/mds. 26104

Hao, Y. H., Doyle, J. M., Ramanathan, S., Gomez, T. S., Jia, D., Xu, M., et al. (2013). Regulation of WASH-dependent actin polymerization and protein trafficking by ubiquitination. Cell 152, 1051-1064. doi: 10.1016/j.cell.2013.01.051

Harbour, M. E., Breusegem, S. Y. A., Antrobus, R., Freeman, C., Reid, E., and Seaman, M. N. J. (2010). The cargo-selective retromer complex is a recruiting hub for protein complexes that regulate endosomal tubule dynamics. J. Cell Sci. 123, 3703-3717. doi: 10.1242/jcs.071472

Harbour, M. E., Breusegem, S. Y., and Seaman, M. N. J. (2012). Recruitment of the endosomal WASH complex is mediated by the extended 'tail' of Fam 21 binding to the retromer protein Vps35. Biochem. J. 442, 209-220. doi: 10. 1042/BJ20111761

Harrison, M. S., Hung, C. S., Liu, T. T., Christiano, R., Walther, T. C., and Burd, C. G. (2014). A mechanism for retromer endosomal coat complex assembly with cargo. Proc. Natl. Acad. Sci. U S A 111, 267-272. doi: 10.1073/pnas. 1316482111

Harterink, M., Port, F., Lorenowicz, M. J., McGough, I. J., Silhankova, M., Betist, M. C., et al. (2011). A SNX3-dependent retromer pathway mediates retrograde transport of the Wnt sorting receptor Wntless and is required for Wnt secretion. Nat. Cell Biol. 13, 914-923. doi: 10.1038/ncb2281

Helfer, E., Harbour, M. E., Henriot, V., Lakisic, G., Sousa-Blin, C., Volceanov, L., et al. (2013). Endosomal recruitment of the WASH complex: active sequences and mutations impairing interaction with the retromer. Biol. Cell 105, 191-207. doi: 10.1111/boc.201200038

Heneka, M. T., Kummer, M. P., Stutz, A., Delekate, A., Schwartz, S., VieiraSaecker, A., et al. (2013). NLRP3 is activated in Alzheimer's disease and 
contributes to pathology in APP/PS1 mice. Nature 493, 674-678. doi: 10. 1038/nature11729

Hermey, G. (2009). The Vps10p-domain receptor family. Cell. Mol. Life Sci. 66, 2677-2689. doi: 10.1007/s00018-009-0043-1

Heydorn, A., Søndergaard, B. P., Ersbøll, B., Holst, B., Nielsen, F. C., Haft, C. R., et al. (2004). A library of 7TM receptor C-terminal tails. Interactions with the proposed post-endocytic sorting proteins ERMbinding phosphoprotein 50 (EBP50), N-ethylmaleimide-sensitive factor (NSF), sorting nexin 1 (SNX1) and G protein-coupled receptor-associated sorting protein (GASP). J. Biol. Chem. 279, 54291-54303. doi: 10.1074/jbc.m4061 69200

Hsu, V. W., Bai, M., and Li, J. (2012). Getting active: protein sorting in endocytic recycling. Nat. Rev. Mol. Cell Biol. 13, 323-328. doi: 10.1038/nrm3332

Huotari, J., and Helenius, A. (2011). Endosome maturation. EMBO J. 30, 3481-3500. doi: 10.1038/emboj.2011.286

Jean, S., and Kiger, A. A. (2012). Coordination between RAB GTPase and phosphoinositide regulation and functions. Nat. Rev. Mol. Cell Biol. 13, 463-470. doi: 10.1038/nrm3379

Jia, D., Gomez, T. S., Billadeau, D. D., and Rosen, M. K. (2012). Multiple repeat elements within the FAM21 tail link the WASH actin regulatory complex to the retromer. Mol. Biol. Cell 23, 2352-2361. doi: 10.1091/mbc.E1112-1059

Jia, D., Gomez, T. S., Metlagel, Z., Umetani, J., Otwinowski, Z., Rosen, M. K., et al. (2010). WASH and WAVE actin regulators of the Wiskott-Aldrich syndrome protein (WASP) family are controlled by analogous structurally related complexes. Proc. Natl. Acad. Sci. U S A 107, 10442-10447. doi: 10. 1073/pnas.0913293107

Johannes, L., and Popoff, V. (2008). Tracing the retrograde route in protein trafficking. Cell 135, 1175-1187. doi: 10.1016/j.cell.2008.12.009

Joubert, L., Hanson, B., Barthet, G., Sebben, M., Claeysen, S., Hong, W., et al. (2004). New sorting nexin (SNX27) and NHERF specifically interact with the 5-HT4a receptor splice variant: roles in receptor targeting. J. Cell Sci. 117, 5367-5379. doi: 10.1242/jcs.01379

Kaifu, T., Nakahara, J., Inui, M., Mishima, K., Momiyama, T., Kaji, M., et al. (2003). Osteopetrosis and thalamic hypomyelinosis with synaptic degeneration in DAP12-deficient mice. J. Clin. Invest. 111, 323-332. doi: 10.1172/jci 16923

Kajii, Y., Muraoka, S., Hiraoka, S., Fujiyama, K., Umino, A., and Nishikawa, T. (2003). A developmentally regulated and psychostimulant-inducible novel rat gene mrtl encoding PDZ-PX proteins isolated in the neocortex. Mol. Psychiatry 8, 434-444. doi: 10.1038/sj.mp.4001258

Kingston, D., Chang, H., Ensser, A., Lee, H. R., Lee, J., Lee, S. H., et al. (2011). Inhibition of retromer activity by herpesvirus saimiri tip leads to CD4 downregulation and efficient T cell transformation. J. Virol. 85, 10627-10638. doi: 10.1128/JVI.00757-11

Kipkorir, T., Tittman, S., Botsios, S., and Manuelidis, L. (2014). Highly infectious CJD particles lack prion protein but contain many viral-linked peptides by LCMS/MS. J. Cell. Biochem. 115, 2012-2021. doi: 10.1002/jcb.24873

Koschmidder, E., Mollenhauer, B., Kasten, M., Klein, C., and Lohmann, K. (2014). Mutations in VPS26A are not a frequent cause of Parkinson's disease. Neurobiol. Aging 35, 1512.e1-1512.e2. doi: 10.1016/j.neurobiolaging.2013. 12.016

Lakadamyali, M., Rust, M. J., and Zhuang, X. W. (2006). Ligands for clathrinmediated endocytosis are differentially sorted into distinct populations of early endosomes. Cell 124, 997-1009. doi: 10.1016/j.cell.2005.12.038

Lane, R. F., Raines, S. M., Steele, J. W., Ehrlich, M. E., Lah, J. A., Small, S. A., et al. (2010). Diabetes-associated SorCS1 regulates Alzheimer's amyloidbeta metabolism: evidence for involvement of SorL1 and the retromer complex. J. Neurosci. 30, 13110-13115. doi: 10.1523/JNEUROSCI.387210.2010

Lane, R. F., Steele, J. W., Cai, D., Ehrlich, M. E., Attie, A. D., and Gandy, S. (2013). Protein sorting motifs in the cytoplasmic tail of SorCS1 control generation of Alzheimer's amyloid-beta peptide. J. Neurosci. 33, 7099-7107. doi: 10. 1523/JNEUROSCI.5270-12.2013

Lane, R. F., St George-Hyslop, P., Hempstead, B. L., Small, S. A., Strittmatter, S. M., and Gandy, S. (2012). Vps10 family proteins and the retromer complex in aging-related neurodegeneration and diabetes. J. Neurosci. 32, 14080-14086. doi: 10.1523/JNEUROSCI.3359-12.2012
Lauffer, B. E., Melero, C., Temkin, P., Lei, C., Hong, W., Kortemme, T., et al. (2010). SNX27 mediates PDZ-directed sorting from endosomes to the plasma membrane. J. Cell Biol. 190, 565-574. doi: 10.1083/jcb.201 004060

Linhart, R., Wong, S. A., Cao, J., Tran, M., Huynh, A., Ardrey, C., et al. (2014). Vacuolar protein sorting 35 (Vps35) rescues locomotor deficits and shortened lifespan in Drosophila expressing a Parkinson's disease mutant of LeucineRich Repeat Kinase 2 (LRRK2). Mol. Neurodegener. 9:23. doi: 10.1186/17501326-9-23

Liu, W., Tang, F. L., Erion, J., Xiao, H., Ye, J., and Xiong, W. C. (2014). Vps35 haploinsufficiency results in degenerative-like deficit in mouse retinal ganglion neurons and impairment of optic nerve injury-induced gliosis. Mol. Brain 7:10. doi: 10.1186/1756-6606-7-10

Lu, L., and Hong, W. (2014). From endosomes to the trans-Golgi network. Semin. Cell Dev. Biol. 31, 30-39. doi: 10.1016/j.semcdb.2014.04.024

Lu, Q., and Lemke, G. (2001). Homeostatic regulation of the immune system by receptor tyrosine kinases of the Tyro 3 family. Science 293, 306-311. doi: 10. 1126/science. 1061663

Lucin, K. M., O’Brien, C. E., Bieri, G., Czirr, E., Mosher, K. I., Abbey, R. J., et al. (2013). Microglial beclin 1 regulates retromer trafficking and phagocytosis and is impaired in Alzheimer's disease. Neuron 79, 873-886. doi: 10.1016/j.neuron. 2013.06.046

Lunn, M. L., Nassirpour, R., Arrabit, C., Tan, J., McLeod, I., Arias, C. M., et al. (2007). A unique sorting nexin regulates trafficking of potassium channels via a PDZ domain interaction. Nat. Neurosci. 10, 1249-1259. doi: 10.1038/ nn1953

Maxfield, F. R., and McGraw, T. E. (2004). Endocytic recycling. Nat. Rev. Mol. Cell Biol. 5, 121-132. doi: 10.1038/nrm1315

McDonough, J. A., Newton, H. J., Klum, S., Swiss, R., Agaisse, H., and Roy, C. R. (2013). Host pathways important for Coxiella burnetii infection revealed by genome-wide RNA interference screening. MBio 4, e00606-e0612. doi: 10. 1128/mbio.00606-12

McGough, I. J., Steinberg, F., Jia, D., Barbuti, P. A., McMillan, K. J., Heesom, K. J., et al. (2014). Retromer binding to FAM21 and the WASH complex is perturbed by the Parkinson disease-linked VPS35(D620N) mutation. Curr. Biol. 24, 1670-1676. doi: 10.1016/j.cub.2014. 06.024

Mehmedbasic, A., Christensen, S. K., Nilsson, J., Rüetschi, U., Gustafsen, C., Poulsen, A. S., et al. (2015). SorLA complement-type repeat domains protect the amyloid precursor protein against processing. J. Biol. Chem. 290, 3359-3376. doi: 10.1074/jbc.M114.619940

Miura, E., Hasegawa, T., Konno, M., Suzuki, M., Sugeno, N., Fujikake, N., et al. (2014). VPS35 dysfunction impairs lysosomal degradation of $\alpha$-synuclein and exacerbates neurotoxicity in a Drosophila model of Parkinson's disease. Neurobiol. Dis. 71, 1-13. doi: 10.1016/j.nbd.2014. 07.014

Morabito, M. V., Berman, D. E., Schneider, R. T., Zhang, Y., Leibel, R. L., and Small, S. A. (2014). Hyperleucinemia causes hippocampal retromer deficiency linking diabetes to Alzheimer's disease. Neurobiol. Dis. 65, 188-192. doi: 10. 1016/j.nbd.2013.12.017

Muhammad, A., Flores, I., Zhang, H., Yu, R., Staniszewski, A., Planel, E., et al. (2008). Retromer deficiency observed in Alzheimer's disease causes hippocampal dysfunction, neurodegeneration and Abeta accumulation. Proc. Natl. Acad. Sci. U S A 105, 7327-7332. doi: 10.1073/pnas.08025 45105

Munsie, L. N., Milnerwood, A. J., Seibler, P., Beccano-Kelly, D. A., Tatarnikov, I., Khinda, J., et al. (2015). Retromer-dependent neurotransmitter receptor trafficking to synapses is altered by the Parkinson's disease VPS35 mutation p.D620N. Hum. Mol. Genet. 24, 1691-1703. doi: 10.1093/hmg/ ddu582

Nisar, S., Kelly, E., Cullen, P. J., and Mundell, S. J. (2010). Regulation of P2Y1 receptor traffic by sorting Nexin 1 is retromer independent. Traffic 11, 508-519. doi: 10.1111/j.1600-0854.2010.01035.x

Norwood, S. J., Shaw, D. J., Cowieson, N. P., Owen, D. J., Teasdale, R. D., and Collins, B. M. (2011). Assembly and solution structure of the core retromer protein complex. Traffic 12, 56-71. doi: 10.1111/j.1600-0854.2010.01124.x

Okada, H., Zhang, W., Peterhoff, C., Hwang, J. C., Nixon, R. A., Ryu, S. H., et al. (2010). Proteomic identification of sorting nexin 6 as a negative regulator of 
BACE1-mediated APP processing. FASEB J. 24, 2783-2794. doi: 10.1096/fj.09146357

Popoff, V., Mardones, G. A., Tenza, D., Rojas, R., Lamaze, C., Bonifacino, J. S., et al. (2007). The retromer complex and clathrin define an early endosomal retrograde exit site. J. Cell Sci. 120, 2022-2031. doi: 10.1242/jcs.003020

Prada, I., Ongania, G. N., Buonsanti, C., Panina-Bordignon, P., and Meldolesi, J. (2006). Triggering receptor expressed in myeloid cells 2 (TREM2) trafficking in microglial cells: continuous shuttling to and from the plasma membrane regulated by cell stimulation. Neuroscience 140, 1139-1148. doi: 10.1016/j. neuroscience.2006.03.058

Priya, A., Kalaidzidis, I. V., Kalaidzidis, Y., Lambright, D., and Datta, S. (2015). Molecular Insights into Rab7-mediated endosomal recruitment of core retromer: deciphering the role of Vps26 and Vps35. Traffic 16, 68-84. doi: 10. $1111 /$ tra. 12237

Reitz, C. (2015). The role of the retromer complex in aging-related neurodegeneration: a molecular and genomic review. Mol. Genet. Genomics 290, 413-427. doi: 10.1007/s00438-014-0939-9

Reitz, C., Tokuhiro, S., Clark, L. N., Conrad, C., Vonsattel, J. P., Hazrati, L. N., et al. (2011). SORCS1 Alters amyloid precursor protein processing and variants may increase Alzheimer's disease risk. Ann. Neurol. 69, 47-64. doi: 10.1002/ana. 22308

Rogaeva, E., Meng, Y., Lee, J. H., Gu, Y., Kawarai, T., Zou, F., et al. (2007). The neuronal sortilin-related receptor SORL1 is genetically associated with Alzheimer disease. Nat. Genet. 39, 168-177. doi: 10.1038/ng1943

Rojas, R., van Vlijmen, T., Mardones, G. A., Prabhu, Y., Rojas, A. L., Mohammed, S., et al. (2008). Regulation of retromer recruitment to endosomes by sequential action of Rab5 and Rab7. J. Cell Biol. 183, 513-526. doi: 10.1083/jcb.200 804048

Ross, O. A., Cook, C., and Petrucelli, L. (2015). Linking the VPS35 and EIF4G1 pathways in Parkinson's disease. Neuron 85, 1-3. doi: 10.1016/j.neuron.2014. 12.045

Scherzer, C. R., Offe, K., Gearing, M., Rees, H. D., Fang, G. F., Heilman, C. J., et al. (2004). Loss of apolipoprotein E receptor LR11 in Alzheimer disease. Arch. Neurol. 61, 1200-1205. doi: 10.1001/archneur.61.8.1200

Schmidt, V., Baum, K., Lao, A., Rateitschak, K., Schmitz, Y., Teichmann, A., et al. (2012). Quantitative modelling of amyloidogenic processing and its influence by SORLA in Alzheimer's disease. EMBO J. 31, 187-200. doi: 10.1038/emboj. 2011.352

Schmidt, V., Sporbert, A., Rohe, M., Reimer, T., Rehm, A., Andersen, O. M., et al. (2007). SorLA/LR11 regulates processing of amyloid precursor protein via interaction with adaptors GGA and PACS-1. J. Biol. Chem. 282, 32956-32964. doi: $10.1074 /$ jbc.m705073200

Seaman, M. N. (2004). Cargo-selective endosomal sorting for retrieval to the Golgi requires retromer. J. Cell Biol. 165, 111-122. doi: 10.1083/jcb.200312034

Seaman, M. N., Gautreau, A., and Billadeau, D. D. (2013). Retromer-mediated endosomal protein sorting: all WASHed up!. Trends Cell Biol. 23, 522-528. doi: 10.1016/j.tcb.2013.04.010

Seaman, M. N. J., Harbour, M. E., Tattersall, D., Read, E., and Bright, N. (2009). Membrane recruitment of the cargo-selective retromer subcomplex is catalysed by the small GTPase Rab7 and inhibited by the Rab-GAP TBC1D5. J. Cell Sci. 122, 2371-2382. doi: 10.1242/jcs. 048686

Seaman, M. N., McCaffery, J. M., and Emr, S. D. (1998). A membrane coat complex essential for endosome-to-Golgi retrograde transport in yeast. J. Cell Biol. 142, 665-681. doi: 10.1083/jcb.142.3.665

Shannon, B., Soto-Ortolaza, A., Rayaprolu, S., Cannon, H. D., Labbé, C., Benitez, B. A., et al. (2014). Genetic variation of the retromer subunits VPS26A/BVPS29 in Parkinson's disease. Neurobiol. Aging 35, 1958.e1-1958.e2. doi: 10. 1016/j.neurobiolaging.2014.03.004

Shi, H., Rojas, R., Bonifacino, J. S., and Hurley, J. H. (2006). The retromer subunit Vps26 has an arrestin fold and binds Vps35 through its C-terminal domain. Nat. Struct. Mol. Biol. 13, 540-548. doi: 10.1038/ nsmb1103

Small, S. A., and Duff, K. (2008). Linking Abeta and tau in late-onset Alzheimer's disease: a dual pathway hypothesis. Neuron 60, 534-542. doi: 10.1016/j.neuron. 2008.11.007

Small, S. A., Kent, K., Pierce, A., Leung, C., Kang, M. S., Okada, H., et al. (2005). Model-guided microarray implicates the retromer complex in Alzheimer's disease. Ann. Neurol. 58, 909-919. doi: 10.1002/ana. 20667

Spillantini, M. G., Schmidt, M. L., Lee, V. M., Trojanowski, J. Q., Jakes, R., and Goedert, M. (1997). Alpha-synuclein in Lewy bodies. Nature 388, 839-840. doi: $10.1038 / 42166$

Steinberg, F., Gallon, M., Winfield, M., Thomas, E. C., Bell, A. J., Heesom, K. J., et al. (2013). A global analysis of SNX27-retromer assembly and cargo specificity reveals a function in glucose and metal ion transport. Nat. Cell Biol. 15, 461-471. doi: 10.1038/ncb2721

Sullivan, C. P., Jay, A. G., Stack, E. C., Pakaluk, M., Wadlinger, E., Fine, R. E., et al. (2011). Retromer disruption promotes amyloidogenic APP processing. Neurobiol. Dis. 43, 338-345. doi: 10.1016/j.nbd.2011. 04.002

Tan, J., and Evin, G. (2012). Beta-site APP-cleaving enzyme 1 trafficking and Alzheimer's disease pathogenesis. J. Neurochem. 120, 869-880. doi: 10.1111/j. 1471-4159.2011.07623.x

Tang, F. L., Liu, W., Hu, J. X., Erion, J. R., Ye, J., Mei, L., et al. (2015). VPS35 deficiency or mutation causes dopaminergic neuronal loss by impairing mitochondrial fusion and function. Cell Rep. 12, 1631-1643. doi: 10.1016/j. celrep.2015.08.001

Temkin, P., Lauffer, B., Jäger, S., Cimermancic, P., Krogan, N. J., and von Zastrow, M. (2011). SNX27 mediates retromer tubule entry and endosome-to-plasma membrane trafficking of signalling receptors. Nat. Cell Biol. 13, 715-721. doi: 10.1038/ncb2252

van Weering, J. R., Sessions, R. B., Traer, C. J., Kloer, D. P., Bhatia, V. K., Stamou, D., et al. (2012). Molecular basis for SNX-BAR-mediated assembly of distinct endosomal sorting tubules. EMBO J. 31, 4466-4480. doi: 10.1038/emboj. 2012.283

Vardarajan, B. N., Bruesegem, S. Y., Harbour, M. E., Inzelberg, R., Friedland, R., St George-Hyslop, P., et al. (2012). Identification of Alzheimer disease-associated variants in genes that regulate retromer function. Neurobiol. Aging 33, 2231.e15-2231.e30. doi: 10.1016/j.neurobiolaging.2012. 04.020

Vilariño-Güell, C., Wider, C., Ross, O. A., Dachsel, J. C., Kachergus, J. M., Lincoln, S. J., et al. (2011). VPS35 mutations in Parkinson disease. Am. J. Hum. Genet. 89, 162-167. doi: 10.1016/j.ajhg.2011.06.001

Wales, P., Pinho, R., Lázaro, D. F., and Outeiro, T. F. (2013). Limelight on alpha-synuclein: pathological and mechanistic implications in neurodegeneration. J. Parkinsons. Dis. 3, 415-459. doi: 10.3233/JPD130216

Wang, D., Guo, M., Liang, Z., Fan, J., Zhu, Z., Zang, J., et al. (2005). Crystal structure of human vacuolar protein sorting protein 29 reveals a phosphodiesterase/nuclease-like fold and two protein-protein interaction sites. J. Biol. Chem. 280, 22962-22967. doi: 10.1074/jbc.m500464200

Wang, X., Huang, T., Zhao, Y., Zheng, Q., Thompson, R. C., Bu, G., et al. (2014). Sorting nexin 27 regulates Abeta production through modulating gammasecretase activity. Cell Rep. 9, 1023-1033. doi: 10.1016/j.celrep.2014.09.037

Wang, C. L., Tang, F. L., Peng, Y., Shen, C. Y., Mei, L., and Xiong, W. C. (2012). VPS35 regulates developing mouse hippocampal neuronal morphogenesis by promoting retrograde trafficking of BACE1. Biol. Open 1, 1248-1257. doi: 10. 1242/bio.20122451

Wang, W., Wang, X., Fujioka, H., Hoppel, C., Whone, A. L., Caldwell, M. A., et al. (2016). Parkinson's disease-associated mutant VPS35 causes mitochondrial dysfunction by recycling DLP1 complexes. Nat. Med. 22, 54-63. doi: 10. 1038/nm.3983

Wang, X., Zhao, Y., Zhang, X., Badie, H., Zhou, Y., Mu, Y., et al. (2013). Loss of sorting nexin 27 contributes to excitatory synaptic dysfunction by modulating glutamate receptor recycling in Down's syndrome. Nat. Med. 19, 473-480. doi: $10.1038 / \mathrm{nm} .3117$

Wang, Y., Zhou, Y., Szabo, K., Haft, C. R., and Trejo, J. (2002). Down-regulation of protease-activated receptor-1 is regulated by sorting nexin 1. Mol. Biol. Cell 13, 1965-1976. doi: 10.1091/mbc.e01-11-0131

Wen, L., Tang, F. L., Hong, Y., Luo, S. W., Wang, C. L., He, W., et al. (2011). VPS35 haploinsufficiency increases Alzheimer's disease neuropathology. J. Cell Biol. 195, 765-779. doi: 10.1083/jcb.201105109

Wyss-Coray, T., Yan, F. R., Lin, A. H. T., Lambris, J. D., Alexander, J. J., Quigg, R. J., et al. (2002). Prominent neurodegeneration and increased plaque 
formation in complement-inhibited Alzheimer's mice. Proc. Natl. Acad. Sci. U $S$ A 99, 10837-10842. doi: 10.1073/pnas.162350199

$\mathrm{Xu}, \mathrm{X}$. (2009). Gamma-secretase catalyzes sequential cleavages of the AbetaPP transmembrane domain. J. Alzheimers Dis. 16, 211-224. doi: 10.3233/JAD2009-0957

Zavodszky, E., Seaman, M. N., Moreau, K., Jimenez-Sanchez, M., Breusegem, S. Y., Harbour, M. E., et al. (2014). Mutation in VPS35 associated with Parkinson's disease impairs WASH complex association and inhibits autophagy. Nat. Commun. 5:3828. doi: 10.1038/ncomms4828

Zhao, X., Nothwehr, S., Lara-Lemus, R., Zhang, B. Y., Peter, H., and Arvan, P. (2007). Dominant-negative behavior of mammalian Vps35 in yeast requires a conserved PRLYL motif involved in retromer assembly. Traffic 8, 1829-1840. doi: 10.1111/j.1600-0854.2007.00658.x

Zimprich, A. (2011). Genetics of Parkinson's disease and essential tremor. Curr. Opin. Neurol. 24, 318-323. doi: 10.1097/WCO.0b013e3283484b87
Züchner, S., Mersiyanova, I. V., Muglia, M., Bissar-Tadmouri, N., Rochelle, J., Dadali, E. L., et al. (2004). Mutations in the mitochondrial GTPase mitofusin 2 cause Charcot-Marie-Tooth neuropathy type 2A. Nat. Genet. 36, 449-451. doi: $10.1038 /$ ng1341

Conflict of Interest Statement: The authors declare that the research was conducted in the absence of any commercial or financial relationships that could be construed as a potential conflict of interest.

Copyright (C) $2016 \mathrm{Li}$, Shah, Zhao and Yang. This is an open-access article distributed under the terms of the Creative Commons Attribution License (CC BY). The use, distribution and reproduction in other forums is permitted, provided the original author(s) or licensor are credited and that the original publication in this journal is cited, in accordance with accepted academic practice. No use, distribution or reproduction is permitted which does not comply with these terms. 